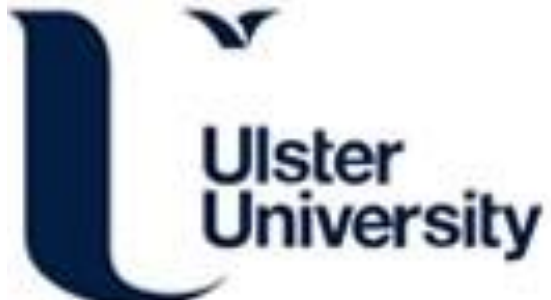

\section{Experimental and modelling studies on the kinetics and mechanisms of thermal degradation of polymethyl methacrylate in nitrogen and air}

Fateh, T., Richard, F., Rogaume, T., \& Joseph, P. (2016). Experimental and modelling studies on the kinetics and mechanisms of thermal degradation of polymethyl methacrylate in nitrogen and air. Journal of Analytical and Applied Pyrolysis, 120, 423-433. https://doi.org/10.1016/j.jaap.2016.06.014

Link to publication record in Ulster University Research Portal

Published in:

Journal of Analytical and Applied Pyrolysis

Publication Status:

Published (in print/issue): 01/07/2016

DOI:

10.1016/j.jaap.2016.06.014

Document Version

Author Accepted version

\section{General rights}

Copyright for the publications made accessible via Ulster University's Research Portal is retained by the author(s) and / or other copyright owners and it is a condition of accessing these publications that users recognise and abide by the legal requirements associated with these rights.

\section{Take down policy}

The Research Portal is Ulster University's institutional repository that provides access to Ulster's research outputs. Every effort has been made to ensure that content in the Research Portal does not infringe any person's rights, or applicable UK laws. If you discover content in the Research Portal that you believe breaches copyright or violates any law, please contact pure-support@ulster.ac.uk. 


\section{Experimental and modelling studies on the kinetics and mechanisms of thermal}

degradation of polymethyl methacrylate in nitrogen and air

Talal FATEH ${ }^{\mathrm{a}}$, Franck Richard ${ }^{\mathrm{b}}$, Thomas ROGAUME ${ }^{\mathrm{b}}$ and Paul JOSEPH ${ }^{\mathrm{c}}$.

a) School of the Built Environment and the Built Environment Research Institute, Ulster University, Newtownabbey, BT37 0QB, County Antrim, Norther Ireland, UK.

b) Institut Pprime, CNRS, Université de Poitiers, ISAE-ENSMA, F-86962 Futuroscope Chasseneuil, France.

c) Centre for Environmental Safety and Risk Engineering, Victoria University, PO Box 14428, Melbourne 8001, Victoria, Australia *Corresponding author: e-mail:t.fateh@ulster.ac.uk 


\section{Highlights}

- TGA and DSC were used to assess the decomposition and phase behaviour of PMMA.

- Gas phase was analysed through FTIR.

- Mechanism of the thermal decomposition of PMMA was proposed.

- Kinetic parameters were calculated by employing a Genetic Algorithm.

- Model was validated for different oxygen concentrations (10.5 and 15 vol.\%). 


\section{ABSTRACT}

Modelling of spread of fires and their extinguishment in solid materials still present a significant challenge. In order to reliably predict the behaviour of a material in a fire scenario, an adequate description of the processes occurring at the gas/solid interface is highly crucial. In this context, those fire scenarios involving polymeric materials are of primary importance because of their increasing use as components in buildings and in transportation. The purpose of this study is to propose an accurate model for the thermal degradation of polymethyl methacrylate (PMMA) by primarily using thermogravimetric analysis (TGA). TGA in non-isothermal conditions, together with Fourier-transform infrared spectroscopy (FT-IR), was applied to investigate the thermal degradation of black PMMA in inert (nitrogen) and oxidizing (air) atmospheres, at different heating rates. The volatile degradation products as well as mass loss history provided sufficient information regarding the kinetics and possible degradation mechanisms of PMMA. A genetic algorithm (GA) was applied to estimate the kinetic parameters, which showed an excellent agreement with corresponding experimental observations for several heating rates and at different atmospheres (0, 10.5, 15 and 21 vol. $\% \mathrm{O}_{2}$ ).

KEYWORDS: polymethyl methacrylate, thermogravimetric analysis, Fourier-transform infrared spectroscopy, mechanism of degradation, gaseous phase, pyrolysis model

\section{NOMENCLATURE LISTING}

\begin{tabular}{|c|c|c|c|}
\hline \multicolumn{4}{|c|}{ Symbol } \\
\hline $\mathrm{m}$ & mass (mg) & $\mathrm{HF}$ & heat flow (mW) \\
\hline Mn & number average molecular weight (g/mol) & GA & genetic algorithm \\
\hline Mw & weight average molecular weight (g/mol) & $\phi$ & fitness \\
\hline $\mathrm{T}$ & temperature $\left({ }^{\circ} \mathrm{C}\right)$ & $\dot{\omega}_{i}$ & reaction rate \\
\hline TG & thermogravimetric & $\alpha$ & $\alpha$-PMMA \\
\hline $\mathrm{W}$ & weight (wt.\%) & $\beta$ & $\beta$-PMMA \\
\hline $\mathrm{C}_{\mathrm{p}}$ & heat capacity $\left(\mathrm{Jg}^{-1} \mathrm{k}^{-1}\right)$ & $\gamma$ & $\gamma$-PMMA \\
\hline TGA & thermogravimetric analysis & $\varepsilon$ & $\varepsilon$-PMMA \\
\hline PDI & polydispersity index & $\alpha$ & $\begin{array}{l}\text { degree of conversion or } \\
\text { degradation }\end{array}$ \\
\hline MLR & mass Loss Rate $\left(\mathrm{ms}^{-1}\right)$ & g & gas \\
\hline $\begin{array}{c}\mathrm{MM} \\
\mathrm{A}\end{array}$ & methyl methacrylate & $\mathrm{p}$ & pyrolysis \\
\hline SEC & size exclusion chromatography & $\mathrm{r}$ & residue \\
\hline TDT & thermal degradation temperature & Sap & sapphire \\
\hline FTIR & Fourier transform infrared spectroscopy & 0 & initial \\
\hline$\rho$ & density $\left(\mathrm{kgm}^{-3}\right)$ & $\mathrm{t}$ & time $(\mathrm{s})$ \\
\hline $\mathrm{n}$ & order of the reaction & $\mathrm{V}$ & reaction stoichiometry \\
\hline A & pre-exponential factor $\left(\mathrm{s}^{-1}\right)$ & $E_{a}$ & activation energy $\left(\mathrm{Jmol}^{-1}\right)$ \\
\hline
\end{tabular}




\begin{tabular}{|c|l|c|l|}
\hline $\mathrm{k}$ & reaction rate constant $\left(\mathrm{s}^{-1}\right)$ & $\beta$ & heating rate $\left({ }^{\circ} \mathrm{Cmin}^{-1}\right)$ \\
\hline $\mathrm{m}_{\text {sap }}$ & mass of sapphire $(\mathrm{g})$ & $\mathrm{C}_{\mathrm{p} \text { sap }}$ & $\begin{array}{l}\text { heat capacity for the sapphire } \\
\left(\mathrm{Jg}^{-1} \mathrm{k}^{-1}\right)\end{array}$ \\
\hline Уo2 $_{\text {o }}$ & mass fraction of oxygen & $\begin{array}{l}\mathrm{HF}_{\text {sap }} \\
(\mathrm{mW})\end{array}$ & $\begin{array}{l}\text { heat flow for the sapphire } \\
\text { (n) }\end{array}$ \\
\hline
\end{tabular}

\section{INTRODUCTION}

Over the past several decades, polymeric materials are being increasingly used as building components, house-hold articles and in transportation. However, these materials can be highly combustible under degradative conditions and in oxidative atmospheres. Thus, it is important to understand how polymers behave in a fire scenario, and also to be able to explain the complex physio-chemical processes and associated coupling of the reactions between condensed and gas phases that lead to a sustainable flaming combustion.

Generally, fire safety investigations are commonly done using specific models of simulation. In these models, the thermal effect is investigated through a "model of pyrolysis", where degradation of solid materials is treated classically. For instance, the calculations follow directly from heat release rates, where the effective heat of combustion is treated as a constant, or a kinetic model is assumed permitting calculation of the mass loss rate using a global reaction (generally an Arrhenius-type reaction with one or two steps) [1-3]. The above assumptions could generate several errors, notably through a poor description of the rate process(s), and also owing to the fact that the thermal degradation of different fuels takes place in several steps (not necessarily by one or two steps).

The kinetics of degradation of solid fuels can be described by different models of different complexities. They can be also divided into two main categories: simple one-step global models and detailed degradation models (with multi-step reaction mechanisms and semi-global reaction mechanisms). However, the chemical processes underpinning these models are not generally well understood. In order that these models to be implemented, a set of apparent kinetic parameters are needed to be determined for each step of the degradation process. On the contrary, often degradation kinetic data are only empirical in nature, and are considered in most cases to be a firstorder reaction, with little or no justification behind this choice [1-3]. In actual practice, an accurate determination of the kinetic parameters of material undergoing thermal degradation is crucial for predicting its behaviour in a fire. 
The overall aim of the present study is to propose a new model of pyrolysis by employing a systematic and thorough analysis of various attributes of degradation of PMMA. The primary objective is to determine the various steps of the degradation and subsequently to describe the rate of each degradation reaction with a view to proposing the best realistic model possible. Over the past ten years, newer approaches to model the pyrolysis of different fuels have been proposed and developed, notably by Rein et al. [4-5], Lautenberger et al. [6], and Matala [7]. These studies used a similar methodology- i.e. from the evolution of the mass loss rates, obtained during TGA investigations, the authors proposed various mechanisms of degradation and then calculated the kinetic parameters for each of such reactions. However, the main drawback of such investigations was that none of them gave due consideration regarding the gaseous phase component(s). In fact, it is crucial to gauge the gaseous products of combustion, as this would enable one to formulate the degradative steps involved in the condensed phase that led to their production in the first place. Therefore, a close examination of both the solid and gaseous phases is pivotal in developing a scientifically robust and reliable thermal degradation model.

Thermogravimetric analysis (TGA) is the most conventional measurement technique to study the decomposition of materials [8]. This technique, generally, provides information that allows one to infer the probable decomposition mechanisms of solid materials in pre-set experimental conditions. In the present study, TGA technique was coupled with a Fourier-transform infrared spectroscopy (FTIR) in order to derive the rate parameters and to elucidate the kinetics of the mass loss rate of the solid. The technique also, in tandem, enabled us to identify the major gaseous species that emanated from the degrading solid substrate in real time. Thus by coupling data obtained from both phases allowed us to describe the decomposition mechanism(s) that are in agreement with the most probable physiochemical processes accompanying the degradation of PMMA. Credible and scientific analyses of the changes in solid phase, as well as the real time of analyses of gaseous components as a function of time (or temperature), are rarely reported in the literature.

In the present work, we focussed our efforts to clarify the thermal degradation and kinetic processes of non-charring thermoplastic polymers, such as PMMA, which has already been the subject of numerous publications [9-19]. The mechanisms and kinetics of the processes underlying the degradation of PMMA have been examined by employing various techniques, and also under several environments that included vacuum, nitrogen, oxygen, argon and helium. However, there are only fewer reports in the literature regarding its degradation studied under normal atmospheric conditions (i.e. air as the medium) [6, 10, 13, 15-16]. It should be also noted that such reports also widely differ in the identification of the number and nature of various degradative steps. Generally, 
it is established for PMMA that the thermal degradation is initiated by the scission of weaker links (for example, at the end-groups) and random scissions, followed by a de-propagation step, and a first-order termination reaction. PMMA also undergoes almost complete degradation, leading to little or no char. However, a very nominal amount of char can be formed by the elimination of methoxycarbonyl side chains, under an oxidative atmosphere, between $370-420^{\circ} \mathrm{C}$. It is highly relevant to note here that the disagreement with regard to the degradation steps and/or associated products, among various reports, could primarily stem from the fact that solid substrates under consideration could widely vary in terms of their micro-structures and morphology. For instance, the molecular weights and its distribution, micro and nature and distribution of minor structures, weak linkages, nature of end groups, etc. could all vary amongst the substrates that were studied. However, by and large, PMMA is considered to yield almost quantitative yield of its monomer through a first order degradative pathway.

\section{MATERIALS AND METHODS}

Generally, unmodified PMMA is a colourless and transparent material, but for some applications where a colour is required, an appropriate additive (i.e. a colourant) is added. In the present work virgin polymer, mixed with a colourant (black), was used. This sample is often referred to as black PMMA, or Altuglas, and was supplied by Vacour company (see Table 1 for the elemental composition). The molecular weights and their distribution were obtained through size exclusion chromatography (SEC) using an Agilent Technologies instrument which was previously calibrated with a polystyrene standard. Samples of 25 and $70 \mathrm{mg}$ (1 and 2 in Table 2) were dissolved in the chloroform and then were injected in SEC instrument. Table 2 also furnishes number average molecular weight $(\mathrm{Mn})$, weight average molecular weight $(\mathrm{Mw})$ and polydispersity index PDI (PDI used as a measure of the broadness of a molecular weight distribution of a polymer, and it is the ratio of Mw over Mn).

\section{Experimental procedures}

The TGA-DSC/FTIR system consisted of a Mettler-Toledo TGA/DSC1 thermo-balance coupled to a Nicolet Nexus Fourier transform infrared spectrometer. Powdered samples of the virgin PMMA, having masses ranging from 5 to $7 \mathrm{mg}$, were heated from room temperatures to $1000^{\circ} \mathrm{C}$, at heating rates of 5, 10, 15 and $20^{\circ} \mathrm{C} / \mathrm{min}$. The experiments were conducted in a nitrogen atmosphere, or in air, as the case may be, at a flow rate of $90 \mathrm{~mL} / \mathrm{min}$. All parts of the transfer line for carrying the evolved gases were maintained at $230^{\circ} \mathrm{C}$ with a view to avoiding condensation of the gases. IR 
spectra were recorded in the spectral range of 4000-650 $\mathrm{cm}^{-1}$ with a $4 \mathrm{~cm}^{-1}$ resolution, and were averaged over16 scans. For the kinetic work, we used the normalized thermogravimetric weight loss curves (TG), and first derivatives (with respect to time) of the weight loss curves (DTG), that were initially recorded as a function of time at fixed heating rate(s). The degradation profiles were also followed from the analysis of the evolved volatile products. The residual masses (wt.\%) from TGA under air atmosphere were found to be in the order of $1 \%$, and no residues under nitrogen atmosphere were observed.

It was also observed that the sample sizes and gas flow rates had no noticeable effects on the profiles of the thermograms obtained. Moreover, any apparent diffusion effects owing gaseous or volatile species, with the temperature ramping, were also found to be absent throughout the experimental runs. Therefore, influences of such factors on the input parameters for kinetic calculations can be considered to be a minimum, if at all present. Therefore, by closely following the profiles of the thermograms and correlating this with the composition and nature of the evolved gases, decomposition kinetics could be deduced with more certainty.

\section{RESULTS AND DISCUSSION}

\subsection{Repeatability of the TGA experiments}

All the TGA runs were done in duplicate to check their reproducibility (see for example the two curves in figure 1 ; heating rate $20^{\circ} \mathrm{C} \mathrm{min}^{-1}$ under nitrogen).

\subsection{Heat capacity and the transition temperature of Black PMMA}

Figures 2 shows the differential scanning calorimetric (DSC) traces that primarily depict the enthalpy changes associated with transitions, for example, reversible changes like glass-transition. Generally about $20 \mathrm{mg}$ of the test material is accurately weighed into aluminium pans and then sealed before loading on to the calorimeter. The runs are generally performed in an inert atmosphere, usually in nitrogen, with a pre-set heating rate. In order to eliminate any irreversible transitions, the experimental run and repeated for each material.

Measurements were performed with a heating rate $10^{\circ} \mathrm{C} \min ^{-1}$ under dry nitrogen gas with a flow rate of $50 \mathrm{~mL} \mathrm{~min}^{-1}$ in a DSC instrument. The initial sample mass of the sample was $20.1 \mathrm{mg}$. Figure 
2 depicts the variation of the heat flow as a function of temperature. As can be seen from the figure, the test was done in duplicate to check reproducibility.

The nature of dependence of heat capacity on temperature can be inferred from the result of the above experiment. In fact, DSC measures the differential heat flow to the sample, in comparison to an empty reference pan, by measuring the temperature difference between the sample and reference. The reference and sample crucibles are placed on a sample carrier within a furnace of cylindrical geometry, which generates heat radially toward the centre. Temperature measurements are done by thermocouples in contact with each crucible. One thermal element is shared between the crucibles allowing the temperature difference to be measured as a voltage. Three measurements are necessary for calculating specific heat. First a "baseline" is recorded with the empty pans, yielding a signal bias inherent in the system. Secondly, a reference test is performed in which a sample with a known specific heat is tested for comparison purpose (for example, sapphire). Finally, an experimental sample is tested. The "baseline" allows deduction of any system bias from data, while the reference test allows calculation of specific heat capacity of the experimental sample as a ratio of the reference material's specific heat.

The heat capacity can be then calculated as follows:

$$
C_{p}=\frac{H F \cdot m_{\text {sap }}}{m \cdot H F_{\text {sap }}} \cdot C_{p_{s a p}}
$$

Where $\mathrm{C}_{\mathrm{p}}$ is the heat capacity for the sample $\left(\mathrm{Jg}^{-1} \mathrm{k}^{-1}\right)$; HF is the heat flow for the sample (mW); m sap is the mass of sapphire (g); $\mathrm{m}$ is the mass of sample (g), $\mathrm{C}_{\mathrm{psap}}$ is the heat capacity for the sapphire $\left(\mathrm{Jg}^{-1} \mathrm{k}^{-1}\right)$.

Figure 3 shows the heat capacity of the PMMA sample as a function of temperature- as can be seen, the relationship is almost linear until about $110^{\circ} \mathrm{C}$ and then increases sharply with further increase in temperature. This phenomenon can be attributed to polymer melting/glass transition, or owing to the start of the thermal degradation/volatilization of very small chain segments, if present.

Heat capacity values for PMMA varies to some extent, as reported previously in the literature [2022], and these variations can be partially due to the differences in the temperatures quoted (for example, $1.33 \mathrm{Jg}^{-1} \mathrm{C}^{-1}$ at $25^{\circ} \mathrm{C}$ and $1.42 \mathrm{Jg}^{-1} \mathrm{C}^{-1}$ at $20^{\circ} \mathrm{C}$ ) [21, 22]. In addition, the values also found to be somewhat dependent on the tacticity of polymer chains as well (between 1.6 and $2 \mathrm{Jg}^{-1} \mathrm{C}^{-1}$ at $100^{\circ} \mathrm{C}$ ) [21]. In the present work, heat capacity value obtained at $100^{\circ} \mathrm{C}$ was $1.6 \mathrm{Jg}^{-1} \mathrm{C}^{-1}$, which is in 
the lower end of the range of values reported in the literature [21]. Generally from the figure 3, the heat capacity values between the $0{ }^{\circ} \mathrm{C}$ and $100^{\circ} \mathrm{C}$ can be obtained by the following equation:

$$
\mathrm{C}_{\mathrm{P}}=0.0044 \mathrm{~T}+1.196
$$

Where $\mathrm{C}_{\mathrm{p}}$ is the heat capacity $\left(\mathrm{Jg}^{-1} \mathrm{k}^{-1}\right)$ and $\mathrm{T}$ in the temperature $(\mathrm{K})$.

\subsection{Determination of the glass transition temperature of PMMA}

Glass transition is a reversible change occurring when an amorphous polymeric material is heated or cooled through a particular temperature range, and can be considered as a dynamic phenomenon. Such a transition is characterized by the glass transition temperature, $T_{g}$. Generally on cooling, a polymeric material becomes more brittle (i.e. less elastic), like a glass, and on heating it becomes more elastic and softer. In the case of thermoplastics, glass transition corresponds to the region above which the material can be moulded. The glass transition is a kinetically-controlled phenomenon, and measured values of the glass transition depend on the cooling rate, thermomechanical history of the sample and also the way in which it is measured- say for example, the exact locations along a thermogram obtained through a DSC run. This means that the glass transition temperature depends on the measurement conditions and cannot be very accurately defined, or determined using the DSC technique. In this study, only one glass transition was observed around a temperature of $113^{\circ} \mathrm{C}$, which is different to value reported in literature $105^{\circ} \mathrm{C}$ [22] and $99.3^{\circ} \mathrm{C}$ [23], but is closer to $99-114^{\circ} \mathrm{C}$, given elsewhere [24]. These variations could be attributed to the differences in chain lengths (molecular weights and their distribution) of the polymeric sample in question.

\subsection{Degradation studies of Black PMMA by TGA measurement in nitrogen}

Figure 4a depicts the thermograms of virgin PMMA sample under nitrogen atmosphere, which also indicates the onset of the degradation (around $150-450^{\circ} \mathrm{C}$ ). It can be also seen that as the heating rate is increased, the temperature range at which degradation starts also moved slightly to a higher temperature region, and that the sample is almost completing degraded towards the end of the TGA, leaving little or no char residue.

The corresponding derivative curves (DTG) for PMMA are shown in figure 4b. A closer inspection of the DTG curves seems to suggest that the degradation process in nitrogen is not entirely through a single step. In fact, smaller shoulders immediately prior to the main degradation step can be identified. Manring et al. [9-11] and Kashiwaghi et al. [12-13] have studied in detail the degradation 
processes of PMMA. Ferriol et al. [15] also observed similar profile for the thermograms. It is believed that the thermal degradation of PMMA proceeds through three to four steps, but the primary steps involve end-chain scissions around $360^{\circ} \mathrm{C}$ and random scissions around $400^{\circ} \mathrm{C}$. The subtle differences in the profiles of thermograms reported by various authors could stem primarily from differences in the sample in terms the molecular weights, their distributions, microstructural features of the polymer chains, and possibly from varying instrumental conditions and purity of the nitrogen gas used.

The final step in the thermograms (around $410^{\circ} \mathrm{C}$ ) can be attributed to further fragmentation and subsequent volatilization of carbon-rich residues, and the amount of residue never exceeded $1 \mathrm{wt}$. \% in any case. Holland and Hay [18] observed higher amounts of char residues, and this could result from the elimination of methoxycarbonyl side-group producing char precursors (i.e. unsaturated conjugated system).

Closer examination of the curves also reveals that, under all heating rates, the mass loss rate comprise two peaks separated by about $30^{\circ} \mathrm{C}$. In addition, it can be noted that under an inert atmosphere of nitrogen, the intensity of the second peak is higher than that of the first peak. Mass loss rates increase more readily from temperatures ranges between 300 and $350^{\circ} \mathrm{C}$, and take place until a temperature reaches 400 to $470^{\circ} \mathrm{C}$ range, depending on the heating rate. These observations agree with those reported by Ferriol et al. [15].

\subsection{Degradation studies of Black PMMA by TGA in air}

Figure 5a shows the TGA curves for the thermal degradation of PMMA conducted under air at various heating rates. Here again, the mass of the residue obtained at the end of each run is negligible over all heating rates. Regardless of the heating rate, decomposition of material occurred in the temperature range of $250-400^{\circ} \mathrm{C}$. Furthermore, it was found that the degradation takes place in one major step in air as reported by Wight et al. [16].

It should be noted here that the actual profiles and salient features of the thermograms were more obvious in the first derivative plots, as shown in figure 5b. Generally as compared to the corresponding plots in nitrogen, those in air did reveal the presence of multiple steps, and generally appeared somewhat more complicated. These additional features could be attributed to additional degradative steps of an oxidative nature occurring in air $[6,10,15]$. In Fig. 5b, it is also evident that the onset of the first step degradation is around $245^{\circ} \mathrm{C}$. 
For the smaller heating rates of 5 and $10^{\circ} \mathrm{C} / \mathrm{min}$, the mass loss rate (MLR) evolutions are similar, with an accompanying scaling factor between the two curves. At temperatures about 300 to $330^{\circ} \mathrm{C}$, the MLR becomes more predominant feature in the upper temperature region. At the heating rate of $5^{\circ} \mathrm{C} / \mathrm{min}$, two small mass losses below $300^{\circ} \mathrm{C}$ are also visible. This can be attributed to either very small chain fragments in the sample possibly resulting from any premature termination reactions that could have led to the incorporation of smaller amounts of head to head linkages and/or terminal vinyl bonds in virgin PMMA.

It can be also seen that the curves indicating the evolutions of MLRs for heating rates of 15 and $20^{\circ} \mathrm{C} / \mathrm{min}$ are almost identical, but those observed for lower heating rates (5 and $10^{\circ} \mathrm{C} / \mathrm{min}$ ) have noticeable differences. Generally above $300^{\circ} \mathrm{C}$, steep increases of the MLRs are observed at all heating rates. Any identifiable differences, shown by the MLR curves at different heating rates, can be attributed to changes in the kinetics, and probably to slight variations in mechanistic pathways, of the underpinning degradation processes.

From the analyses of evolution of MLRs, obtained during the TGA experiments in nitrogen and air, one could conclude that under the inert atmosphere the thermal decomposition of PMMA takes place through four successive steps; while under air, even though the thermo-oxidative decomposition of PMMA also takes place in predominantly four steps, some of these could be competing. These results are in agreement with the most recent studies on the thermal degradation of PMMA obtained through a free radical method [12, 15]. It is also believed that the consequence of an oxidative environment is to render the substrate more unstable as the oxygen bi-radical can attack the activated hydrogen at the vinylidene functionality to form a hydroperoxide linkage that can further undergo a $\beta$-scission [12-13]. Oxygen can also promote random scissions. Thus a reduction of the initial induction temperature is comparatively lower in the presence of air (from $280^{\circ} \mathrm{C}$ in nitrogen to $250^{\circ} \mathrm{C}$ in air). In addition, oxidation of any carbonaceous residue formed seems to be accelerated and is also found take place at a lower temperature in an oxidative atmosphere $[12,13,25]$ However, the mechanisms under air are not entirely clear, and there are some disagreements between different authors [4, 12, 15-16].

\subsection{Effect of the oxygen on the thermal degradation}

Subtle differences in the MLRs are more evident when the corresponding DTG curves (at $10^{\circ} \mathrm{C} / \mathrm{min}$ ) in both atmospheres are examined (see figure 6). It is important to note here that these curves are also representative of the corresponding ones under all other conditions of heating. 
As can be seen from the figure 6, the thermal degradation under air occurs relatively faster than under nitrogen. The mass loss rate curves attained the maximal value around $340^{\circ} \mathrm{C}$ under air and $370^{\circ} \mathrm{C}$ under nitrogen. The thermal degradation under nitrogen is almost completely over at a temperature near to $450^{\circ} \mathrm{C}$, whereas under air it is around the $400^{\circ} \mathrm{C}$. It is also evident that the presence of oxygen modified the kinetic parameters, and therefore, it would not possible to reproduce the two curves by using same group of kinetics parameters as input.

\subsection{Mechanisms of the thermal degradation}

With a view to getting more insight into the mechanistic pathways of degradation of PMMA, in the present work, we endeavoured to investigate the nature the gaseous species formed through TGA/FTIR analyses for each heating rate and for both types of atmospheres. Under nitrogen atmosphere, water, $\mathrm{CO}$, methanol, methyl methacrylate monomer (MMA) and $\mathrm{CO}_{2}$ were detected. Moreover, a comparison of the gaseous evolutions of the gas emissions and the corresponding MLR as a function of time closely followed very similar profiles for all the heating rates employed (see for example in figure 7 , at a heating rate of $20^{\circ} \mathrm{C} / \mathrm{min}$ ); also note here that $\mathrm{CO}$ and methanol were only detected in very small quantities, and are not shown in the figure.

It is important to observe here that the various gaseous species are only qualitatively measured and then are arbitrarily converted into their corresponding relative intensities. The Table 3 presents the gas detected during the thermal degradation under inert atmosphere.

The peak of the MLR denotes the formation of MMA. We can also observe a clear correspondence between the evolution of the MLR and emission MMA. MMA appears to be the primary component formed through the main pyrolytic reaction, i.e. through depolymerization process. A second peak corresponding to the generation of $\mathrm{CO}_{2}$ is also observed. The drift in temperature range, between the peak of MLR and of $\mathrm{CO}_{2}$ emission, could be due to the fact that $\mathrm{CO}_{2}$ is being predominantly formed from secondary pyrolytic reactions following on from the depolymerization. At the end of the main degradation, i.e. above $500^{\circ} \mathrm{C}$, formation of $\mathrm{CO}_{2}$ was also noticed- this could be attributed to form from further secondary oxidative reaction of the carbonaceous residue.

From the evolution of gaseous species during the thermal degradation of PMMA under an inert atmosphere, following steps could be formulated:

1. De-polymerization of PMMA to form MMA; 
2. Secondary reactions of MMA and the interaction of MMA and its decomposition products with the solid matrix;

3. De-volatilization of the various secondary products components to form further $\mathrm{CO}_{2}$, and generation of a carbonaceous residue;

4. Further reactions of the char residue at the end of the degradative processes

Under air, methyl methacrylate (MMA), carbon dioxide $\left(\mathrm{CO}_{2}\right)$, water vapour $\left(\mathrm{H}_{2} \mathrm{O}\right)$ and methanol were detected as the primary fractions. The Table 3 presents the gaseous species detected during the thermal degradation under air.

Generally under air, the gaseous evolutions are quite similar for all heating rates, so the evolution of MLR and the gaseous species are only given for a heating rate of $20^{\circ} \mathrm{C} / \mathrm{min}$ (see figure 7).

Under the inert atmosphere, the main gaseous component was found to be methyl methacrylate (MMA). However under air, the components from the thermal degradation of PMMA, in addition to MMA, also consisted of significant amounts of carbon dioxide, methyl methacrylate and water vapour.

For a heating rate of $20^{\circ} \mathrm{C} / \mathrm{min}$ (figure 7), $\mathrm{MMA}, \mathrm{CO}_{2}$ and $\mathrm{H}_{2} \mathrm{O}$ were found to be emitted around the same temperature range, i.e. $\mathrm{ca}$. around $280^{\circ} \mathrm{C}$, which is about $30^{\circ} \mathrm{C}$ after the peak temperature for MLR. The evolutionary peak of MMA has a shoulder peak, as in the case of the MLR curve, but it varies in relative intensity and position. For smaller heating rates, the evolutions of $\mathrm{CO}_{2}$ and $\mathrm{H}_{2} \mathrm{O}$ were observed to be slower, and associated curves consisted only of one peak and appeared after the major peak of the MLR curve. As is expected, the relative intensities of peaks corresponding to evolutions of $\mathrm{CO}_{2}$ and $\mathrm{H}_{2} \mathrm{O}$ were smaller at the slower heating rates, but these also correlated well with the MLR curve as in the case of the highest heating rate of $20^{\circ} \mathrm{C} / \mathrm{min}$.

The differences in the evolutionary rates of gaseous species and evolution of the MLRs, as a function of the heating rate, indicate a strong influence of the diffusion process of oxygen during thermal degradation of PMMA. This observation is agreement with a previous study [26], and also points towards the fact that the overall process of degradation consists of competing reactions. In addition, different chemical moieties formed in the condensed phase (such as $\varepsilon$-PMMA from the $\beta$ PMMA) could also contribute to such degradative pathways.

Through the study of the transformations in the solid phase and evolutions in the gas phase, under all experimental conditions, would enable one to formulate a four step degradation mechanism in 
nitrogen as well as in air, as shown below. The mechanism proposed for thermal degradation under nitrogen also confirms the mechanism proposed previously in the literature [15]. The mechanism proposed presented in Figure 8.

\subsection{Calculation of the kinetics parameters by a genetic algorithm (GA)}

Typically, the degree of conversion or degradation, $\alpha$, can be represented as:

$$
\alpha=\frac{m_{0}-m}{m_{0}-m_{\infty}}
$$

Where $m$ denotes mass of the sample, $m_{0}$ the initial mass and $m_{\infty}$ being the final mass.

$$
\frac{d \alpha}{d t}=k f(\alpha)
$$

Where $f(\alpha)=(1-\alpha)^{n}$, $n$ being order of reaction, and $k$ is the rate constant. According to the Arrhenius rate process:

$$
k=A e^{-E_{a} / R T}
$$

Where $\mathrm{A}$ is the pre-exponential factor $\left(\mathrm{s}^{-1}\right), \mathrm{T}$ is the temperature $(\mathrm{K})$ and $\mathrm{E}_{\mathrm{a}}$ the energy of activation $\left(\mathrm{Jmol}^{-1}\right)$.

For the substrate under consideration (i.e. for PMMA), the final mass, $\mathrm{m}_{\infty} \sim 0$, and we can write:

$$
\alpha=1-\frac{m}{m_{0}}
$$

Therefore, the reaction rate can be written as:

$$
\dot{\omega}_{i}=A e^{-E / R T} m_{i}^{n} y_{O 2}^{\delta}
$$

Where $\mathrm{y}_{\mathrm{O} 2}$ is the mass fraction of oxygen. Here $\delta$ is taken as 1 under air and as 0 under nitrogen.

In the present study we used a genetic algorithm (GA) method which uses an evaluation function that compares the curves of experimental data and calculated ones. The accuracy between the two sets of curves is called the fitness. Many equations of fitness exist in the literature [3-7, 15, 27-28]. In this investigation, we used an equation developed by the LNE (The Laboratory National de Metrology and testing, France) [26], and is given below: 


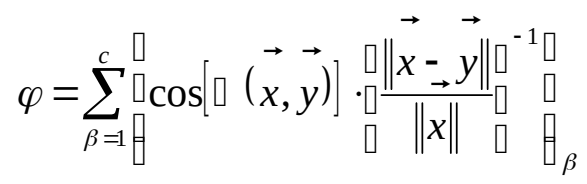

Where

$$
\vec{x}=\frac{d m^{E x p}}{d T} ; \vec{y}=\frac{d m^{\text {Calc }}}{d T}
$$

Where ${ }_{x}$ and $y$ are the arrays of experimental and calculated mass loss rates as a function of the temperature respectively. The mechanism of degradation is shown in Figure 8 (where $v$ is the stoichiometric factor):

While the corresponding mass loss rate for each phase can be represented as:

$$
\begin{aligned}
& \frac{d m_{P M M A}}{d t}=-\omega_{1} \\
& \frac{d m_{\alpha}}{d t}=v_{1} \omega_{1}-\omega_{2} \\
& \frac{d m_{\beta}}{d t}=v_{2} \omega_{2}-\omega_{3} \\
& \frac{d m \gamma}{d t}=v_{3} \omega_{3}-\omega_{4} \\
& \frac{d m_{R}}{d t}=v_{4} \omega_{4}
\end{aligned}
$$

Each reaction is corresponding with four inconnu parameters (A, $E_{a}, n$ and the stoichiometric ones). The optimizations of the parameters were carried out using the GA.

The values of kinetic parameters obtained by optimization method of the genetic algorithm are presented in Table 4. These values correspond to the best value of fitness. The optimization has been conducted over a wide range ( $\log _{10} \mathrm{~A}$ between 1 and 25, $\mathrm{E}_{\mathrm{a}}$ between 40 and $350 \mathrm{kJmol}^{-1}$ and n between 0.1 and 5). The figure 9 represents the comparison between the theoretical and the experimental data under nitrogen.

The kinetic parameters were calculated in two steps. First, the parameters corresponding to thermal degradation under nitrogen were determined. Then calculation of the parameters of the reactions under air was done.

The figure 10 represents the comparison between the theoretical and experimental data, under air, for heating rates chosen in this study. As can be seen from the above figure, the MLR evolution curves, calculated by the degradation model, show a good agreement with the experimental results 
obtained during thermal decomposition process of PMMA. Therefore, it is evident that suggested mechanism along with the kinetic parameters obtained through the GA will allow one to reproduce the experimental MLR curves very closely.

In addition, in order to gain a detailed knowledge regarding the evolutionary profiles of the gaseous species, at each stage that occurs in the condensed phase during thermal degradation, the mass for the raw polymer as well for intermediate material, as a function of temperature, has also been studied for both atmospheres. These results are presented in figure 11 for a heating rate of $10^{\circ} \mathrm{C}$ $\min ^{-1}$; here the temperature ranges where the formation and consumption of each intermediate material can be also identified. It should be also noted that results obtained at this heating rate are representative of the ones obtained for all other heating rates.

Generally, the profiles of the mass loss curves indicate that the initial mass of PMMA changes quickly with increase of temperature, and this could involve the formation of intermediate phases. It can be also noted that the original mass is almost totally consumed when the temperature is above than $350{ }^{\circ} \mathrm{C}$ under nitrogen and $375^{\circ} \mathrm{C}$ under air. In addition, under nitrogen the $\alpha$-PMMA component appears to be present until the temperature reaches $375^{\circ} \mathrm{C}$, whereas the corresponding temperature under air is about $325^{\circ} \mathrm{C}$. Subsequently, the $\beta$-PMMA component seems to be totally consumed totally when the temperature is more than $400{ }^{\circ} \mathrm{C}$ under nitrogen and $375^{\circ} \mathrm{C}$ under air. The final solid phase, the $\mathrm{\gamma}$-PMMA component, is believed to be completely consumed at a temperature around $425^{\circ} \mathrm{C}$ under nitrogen and at about $400^{\circ} \mathrm{C}$ under air. As can also be seen, presence of $\mathrm{O}_{2}$ slows down the induction of the initial thermal degradation of PMMA; however, it accelerates degradation towards the end. These effects can be attributed to the inhibition of the degradative steps, stemming from the bi-radical nature of molecular oxygen, while at higher temperatures $\mathrm{O}_{2}$ molecule facilitates oxidative reactions thus resulting in the conversion of carbonaceous material to its gaseous oxides [9-15].

In fact, the results show that the model is in good agreement with experimental results obtained through TGA at the two concentrations of oxygen (i.e. at 0 and 21 vol.\%). However, owing to the large variations in heating rates and/or availability of oxygen under a real fire scenario, such observations in small-scale controlled heating regimes cannot be applied to actual behaviour of PMMA in real fires [28]. Hence the model and the associated kinetic parameters cannot be validated for real scale fire conditions. 
In order to check the validity of the model, at the current scale and for intermediate oxygen concentrations, theoretical and experimental were compared at oxygen concentrations of 10.5 and 15 vol. \% and at different heating rates (see in figure 12).

As can be seen from figure 12, the model is in good agreement with the experimental data for all the heating rates employed in the present work (notice also that the model data has been obtained by using kinetic parameters reported in the Table 4).

There are several literature precedents where Arrhenius equation has been used [3-7, 31-32] in order to describe reaction rates of thermal degradation processes of solid polymeric materials. Furthermore, several authors used a linear relation between $\log (\mathrm{A})$ and activation energy, $\mathrm{E}_{\mathrm{a}}$ [29, 33]; however, generally, the equation excluded the term related to oxygen concentration (this term is included in the equation given below):

$$
\frac{d \alpha}{d t}=A \exp \left(-E_{a} \mid R T\right)(f \alpha) y_{o 2}{ }^{\delta}
$$

Where $\delta$ is the Kronecker symbol and $\mathrm{Y}_{\mathrm{O} 2}$, the mass fraction of $\mathrm{O}_{2}$; these only considered for oxidative reactions, and it is omitted for pure pyrolytic processes.

It is highly relevant to note here that there is a serious drawback when we use the above form of the equation. For example, the relation yields a finite, however small, value for the rate of reaction even under nominal temperatures, for instance at $20^{\circ} \mathrm{C}$, regardless of the values of other kinetic parameters. This seems to suggest that the material could undergo degradation even at ambient temperatures.

In addition, the real role played by molecular oxygen in the degradation process(s) of PMMA cannot be fully understood, nor could be explained beyond all reasonable doubts. Its probable dual role, i.e. as a catalyst, or as a reactant, depending on the reaction under question cannot be deciphered with certainty. For example, in the case of flaming combustion of PMMA, in a real fire scenario, the concentration term for oxygen needs to be incorporated in the equation, and therefore, molecular oxygen needs to be considered as reactant and not as a catalyst. However, at least in the case of initial stages of degradation (i.e. well before the onset of flaming combustion), oxygen seems to stabilize the PMMA substrate, and in doing so, it does not aid in mass loss $[4,13]$. 
In short, the actual nature and time frame when molecular oxygen switches its preference for its two possible roles cannot be established with any certainty. Moreover, there was no additional information obtainable regarding the exact role of oxygen, through examining the gaseous species emanating from PMMA under nitrogen and air in the present study, as the species identified were almost similar.

In addition, as FTIR technique could not detect $\mathrm{O}_{2}$, owing its infrared inactivity, and therefore the consumption of oxygen could not be observed. Ideally the mass fraction of oxygen, $\mathrm{Y}_{\mathrm{O} 2}$, should be determined during the experiment as it's estimated value by using the GA method gets compensated with other parameters like, A and Ea. In order to avoid such a problem, techniques that can directly and quantitative measure oxygen need to be employed as a complementary requisite.

\section{MAIN CONCLUSIONS}

The thermal degradation of poly (methyl methacrylate) has been assessed using TGA coupled to an FTIR. In the present work, a four-stage degradation process was observed for the PMMA sample under nitrogen and air. The hyphenated technique employed (i.e. TGA/FTIR) did not yield full information regarding thermo-oxidative degradation of PMMA, especially, the role played by molecular oxygen. A genetic algorithm method [25] was effectively employed to predict the overall mass-loss rates during in any given experimental condition. The MLR evolution profiles, calculated by the decomposition model, showed a good agreement with experimental results. The hyphenated technique employed (i.e. TGA/FTIR) did not yield full information regarding thermo-oxidative degradation of PMMA, especially, the role played by molecular oxygen. To obtain a fuller

understating of underpinning physio-chemical processes of thermo-oxidative degradation and ensuing flaming combustion behaviours of PMMA, it is highly desirable to develop an appropriate complementary technique for the real-time measurements of oxygen concentration.

\section{REFERENCES}

1. ASTM E1354, Standard method for heat and visible smoke release rates for materials and products using an oxygen consumption calorimeter.

2. ASTM E1321, Standard method for determining material ignition and flame spread properties.

3. Fateh, T., Richard, F., Rogaume, T., Multi-scale Modelling of the thermal decomposition of a fire retardant plywood, Fire Safety Journal 64: 36-47 (2014). 
4. Rein, G., Lautenberger, C., Fernandez-Pello, C., Torero, J., Urban, D., Application of genetic algorithms and thermogravimetry to determine the kinetics of polyurethane foam in smoldering combustion, Combustion and Flame 146: 95-108 (2006).

5. Lautenberger, C., Rein, G., Fernandez-Pello, C., The Application of a Genetic Algorithm to Estimate Material Properties for Fire Modelling from Bench-Scale Fire Test Data, Fire Safety Journal 41: 204-214 (2006).

6. Lautenberger, C., Fernandez-Pello, C., Generalized Pyrolysis Model for Combustible Solids, Fire Safety Journal 44: 819-839 (2009).

7. Matala, A., Estimation of solid phase reaction parameters for fire simulation, A dissertation for the degree of the degree of Master of Science in Technology in the Degree Programme in Engineering Physics, (2008) University of Technology, Helsinki.

8. Wilkie, C.A., TGA/FTIR: an extremely useful technique for studying polymer degradation, Polymer Degradation and Stability 66: 301-306 (1999).

9. Manring, L.E., Thermal degradation of saturated poly (methyl methacrylate), Macromolecules 21: 528-530 (1988).

10. Manring, L.E., Thermal degradation of poly (methyl methacrylate). 2. Vinyl-terminated polymer, Macromolecules 22: 2673-2677 (1989).

11. Manring, L.E., Thermal degradation of poly (methyl methacrylate). 4. Random side-group scission, Macromolecules 24: 3304-3309 (1991).

12. Kashiwagi, T., Inaba, A., Brown, J.E., Hatada, K., Kitayama, T., Masuda, E., Effects of Weak Linkages on the Thermal and Oxidative Degradation of Poly(methyl methacrylates), Macromolecules 19: 2160-2168 (1986).

13. Kashiwagi, T., Hirata, T., Brown, J.E., Thermal and oxidative degradation of poly (methyl methacrylate) molecular weight, Macromolecules 18: 131-138 (1985).

14. Holland, B.J., Hay, J.N., The value and limitations of non-isothermal kinetics in the study of polymer degradation, Thermochimica Acta 388: 253-273 (2002).

15. Ferriol, M., Gentilhomme, A., Cochez, M., Oget, N., Mieloszynski, J.L., Thermal degradation of poly (methyl methacrylate) (PMMA): modelling of DTG and TG curves, Polymer Degradation and Stability 79: 271-281 (2003).

16. Peterson, J.D., Vyazovkin, S., Wight, C.A., Kinetic Study of Stabilizing Effect of Oxygen on Thermal Degradation of Poly (methyl methacrylate), Journal Physical Chemistry B 103: 80878092 (1999). 
17. Brown, J.E., Kashiwagi, T., Gas Phase Oxygen Effect on Chain Scission and Monomer Content un Bulk Poly(Methyl Methacrylate) degraded by External Thermal Radiation, Polymer Degradation and Stability 52: 1-10 (1996).

18. Holland, B.J., Hay, J.N., The kinetics and mechanisms of the thermal degradation of poly (methyl methacrylate) studied by thermal analysis-Fourier transform infrared spectroscopy, Polymer 42: 4825-4835 (2001).

19. Chiantore, O., Luda di Cortemiglia, MP., Guaita, M., Changes in the thermal degradation of poly (methyl methacrylate), Polymer Degradation and Stability 24: 113-126 (1989).

20. Gaur, U., Lau, S., Wunderlich, B.B., Wunderlich, B., Heat capacity and other thermodynamic propertiers of linear macromolecules, Journal Physical Reference Data 11: 1065-1089 (1982).

21. Soldera, M., Metatla, N., Beaudoin, A., Said, S., Grohens, Y., Heat capacities of both PMMA stereomers: Comparison between atomistic simulation and experimental data, Polymer 51: 2106-2111(2010).

22. Brandrup, J., Immergut, E.H., Grulke, E.A., Polymer Handbook. Wiley, New York, New York, 1999.

23. Gaur, M., Shulka, P., Tiwari, R., Tanwar, A., Singh, S., New approach for the measurement of glass transition temperature of polymer; Indian Journal of Pure and Applied Physics 46: 535539 (2008).

24. Dehennau, C., Dubois, P., Rigid thermoplastic co-extruded structures permitting the obtention of biaxially oriented materials, patent EP0352840 A1. 1990.

25. Dakka, S.M., Jackson, G. S., Torero, J.L., Mechanisms Controlling the Degradation of Poly(methyl methacrylate) Prior to Piloted Ignition, Proceedings of the Combustion Institute 29: 281-287 (2002).

26. Chaos, M., Khan, M.M., Krishnamoorthy, N., De Ris , J.L., Dorofeev,B., Evaluation of optimization schemes and determination of solid fuel properties for CFD fire models using bench-scale pyrolysis tests , Proceedings of the Combustion Institute 33: 2599-2606 (2011).

27. Houck, C.R., Joines, J.A., Kay, M.G., GAOT: A Genetic Algorithm for Function Optimization: A Matlab Implementation, Report NCSU-IE TR 95-09, 1995, http://www.ie.ncsu.edu.

28. Bustamante, L., Experimental and numerical investigation of the thermal decomposition of materials at three scales: application to polyether polyurethane foam used in upholstered furniture. Poitiers University (2009). 
29. Fateh, T., Rogaume, T., Luche, J., Richard, F., Jabouille, F., Kinetic and mechanism of the thermal degradation of a plywood by using thermogravimetry and Fourier-Transformed Infrared Spectroscopy analysis in nitrogen and air atmosphere, Fire Safety Journal 58: 25-37(2013).

30. Fateh, T., Rogaume, T., Luche, J., Richard, F., Jabouille, F., Modelling of the thermal decomposition of a treated plywood from thermo-gravimetry and Fourier-transformed infrared spectroscopy experimental analysis, Journal of Analytical and Applied Pyrolysis 101: 35-44 (2013).

31. Lautenberger, C., A generalized pyrolysis model for combustible solids (Ph.D. thesis), university of California, Berkeley (2007). \www.code.google.com/p/gpyro/.

32. Fateh, T., Etude expérimentale et numérique de la cinétique de décomposition thermique de contre plaqués en bois ( $\mathrm{PhD}$ thesis), Poitiers University (2011).

33. Bal, N., Rein, G., Relevant model complexity for non-charring polymer pyrolysis, Fire Safety journal 61: 36-44 (2013). 
Table 1. Elemental composition of black PMMA.

\begin{tabular}{lc}
\hline Element & $\begin{array}{c}\text { Composition } \\
\text { (wt. \%) }\end{array}$ \\
\hline Carbon (C) & 59.1 \\
Hydrogen (H) & 7.9 \\
Oxygen (O) & 31.9 \\
Nitrogen (N) & $<0.3$ \\
Sulfur (S) & $<0.2$ \\
Chlorine (Cl) & 0.1 \\
Water (H2 $\mathbf{~} \mathbf{~ ) ~}$ & 0.6 \\
\hline
\end{tabular}

Table 2. Characterization data for black PMMA by SEC.

\begin{tabular}{cccc}
\hline Sample & Mn & Mw & PDi \\
\hline $\mathbf{1}$ & 178,670 & 639,340 & 3.6 \\
$\mathbf{2}$ & 150,440 & 578,480 & 3.9 \\
\hline
\end{tabular}

Table 3. Temperature ranges for the evolution of the gaseous species (detected at $20^{\circ} \mathrm{C} \mathrm{min}{ }^{-1}$ under nitrogen).

\begin{tabular}{c|c|c|c|c|c|c}
\hline & \multicolumn{3}{|c|}{ under nitrogen } & \multicolumn{4}{c}{ Under Air } \\
\hline \multirow{3}{*}{ Gas } & \multicolumn{3}{|c|}{ Temperature range } & \multicolumn{3}{c}{ Temperature range } \\
\cline { 2 - 7 } & start & end & $\begin{array}{c}\text { maxim } \\
\text { a }\end{array}$ & start & end & $\begin{array}{c}\text { maxim } \\
\text { a }\end{array}$ \\
\hline Water & $150^{\circ}$ & $500^{\circ}$ & $460^{\circ} \mathrm{C}$ & $260^{\circ}$ & $470^{\circ}$ & $400^{\circ} \mathrm{C}$ \\
vapor & $\mathrm{C}$ & $\mathrm{C}$ & & $\mathrm{C}$ & $\mathrm{C}$ & \\
\hline MMA & $140^{\circ}$ & $450^{\circ}$ & $390^{\circ} \mathrm{C}$ & $115^{\circ} \mathrm{C}$ & $450^{\circ}$ & $345^{\circ} \mathrm{C}$ \\
& $\mathrm{C}$ & $\mathrm{C}$ & & & $\mathrm{C}$ & \\
\hline $\mathrm{CO}_{2}$ & $220^{\circ}$ & $500^{\circ}$ & $420^{\circ} \mathrm{C}$ & $270^{\circ}$ & $470^{\circ}$ & $390^{\circ} \mathrm{C}$ \\
& $\mathrm{C}$ & $\mathrm{C}$ & & $\mathrm{C}$ & $\mathrm{C}$ & \\
\hline methanol & $425^{\circ}$ & $465^{\circ}$ & $440^{\circ} \mathrm{C}$ & $410^{\circ}$ & $445^{\circ}$ & $430^{\circ} \mathrm{C}$ \\
& $\mathrm{C}$ & $\mathrm{C}$ & & $\mathrm{C}$ & $\mathrm{C}$ & \\
\hline $\mathrm{CO}$ & $445^{\circ}$ & $455^{\circ}$ & $450^{\circ} \mathrm{C}$ & - & - & - \\
& $\mathrm{C}$ & $\mathrm{C}$ & & & & \\
\hline
\end{tabular}


Table 4: The kinetic parameters of the reactions calculated by using GA method.

\begin{tabular}{|c|c|c|c|c|c|c|c|c|c|c|}
\hline \multirow{3}{*}{$\begin{array}{l}\text { Reaction } \\
\mathrm{N}^{\circ}\end{array}$} & \multirow{3}{*}{ Substrate } & \multirow{3}{*}{ Product } & \multicolumn{4}{|c|}{ Under nitrogen } & \multicolumn{4}{|c|}{ Under Air } \\
\hline & & & \multicolumn{4}{|c|}{ Kinetic parameters } & \multicolumn{4}{|c|}{ Kinetic parameters } \\
\hline & & & ${ }^{1} \log _{10} \mathrm{~A} \quad\left(\mathrm{~s}^{-}\right.$ & $\mathrm{Ea}\left(\mathrm{kJ} \mathrm{mol}^{-1}\right)$ & $\mathrm{n}$ & & $\begin{array}{c}\log _{10} \mathrm{~A}\left(\mathrm{~s}^{-}\right. \\
\left.{ }^{1}\right)\end{array}$ & $\begin{array}{c}\text { Ea }\left(\mathrm{kJmol}^{-}\right. \\
\left.{ }^{1}\right)\end{array}$ & $\mathrm{n}$ & $v$ \\
\hline 1 & PMMA & $\alpha$ PMMA & 16.5 & 158.0 & 3.9 & 0.98 & 16.00 & 158.00 & 3.90 & 0.98 \\
\hline 2 & $\alpha$ PMMA & $\beta$ PMMA & 10.8 & $154.4 \pm 1$ & 0.85 & 0.60 & 14.83 & 180.00 & 0.75 & 0.83 \\
\hline 3 & $\beta$ PMMA & r PMMA & 17.0 & $161 \pm 1$ & 1 & 0.17 & 10.65 & 144.09 & 0.90 & 0.07 \\
\hline 4 & r PMMA & Residue & 14.3 & 215.0 & 0.83 & 0.02 & 14.11 & 196.00 & 0.735 & 0.02 \\
\hline
\end{tabular}


Figure 1. Mass loss and Mass loss rates versus time for the thermal degradation of PMMA at $20^{\circ} \mathrm{C}$

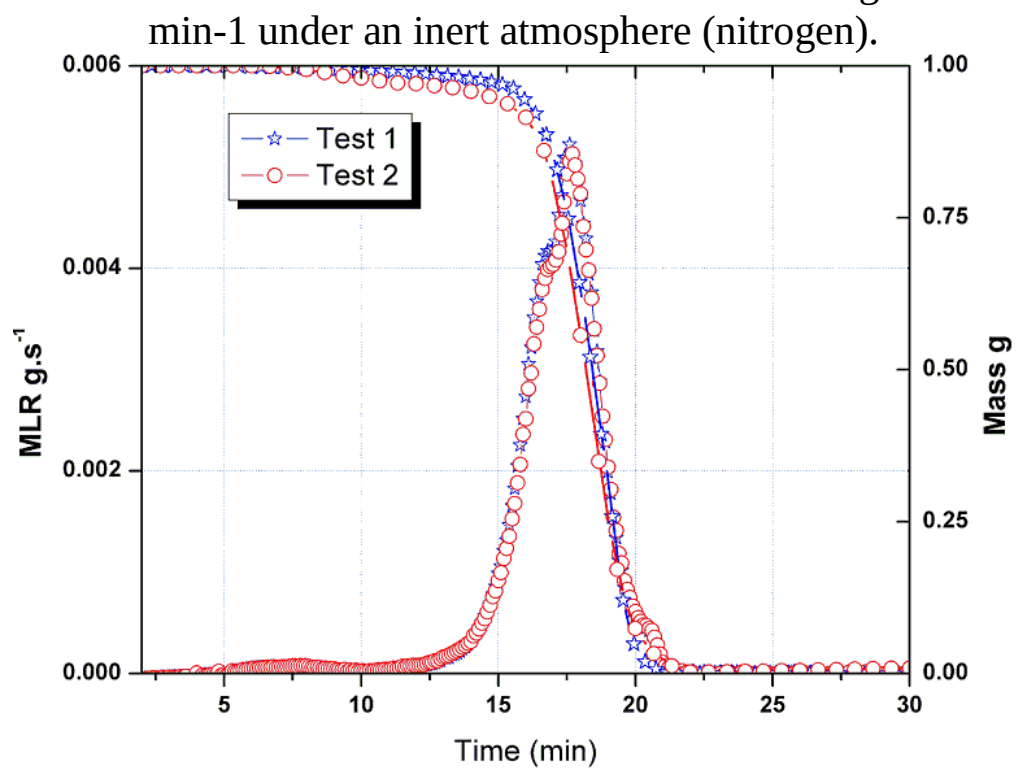

Figure 2. The DSC trace of PMMA.

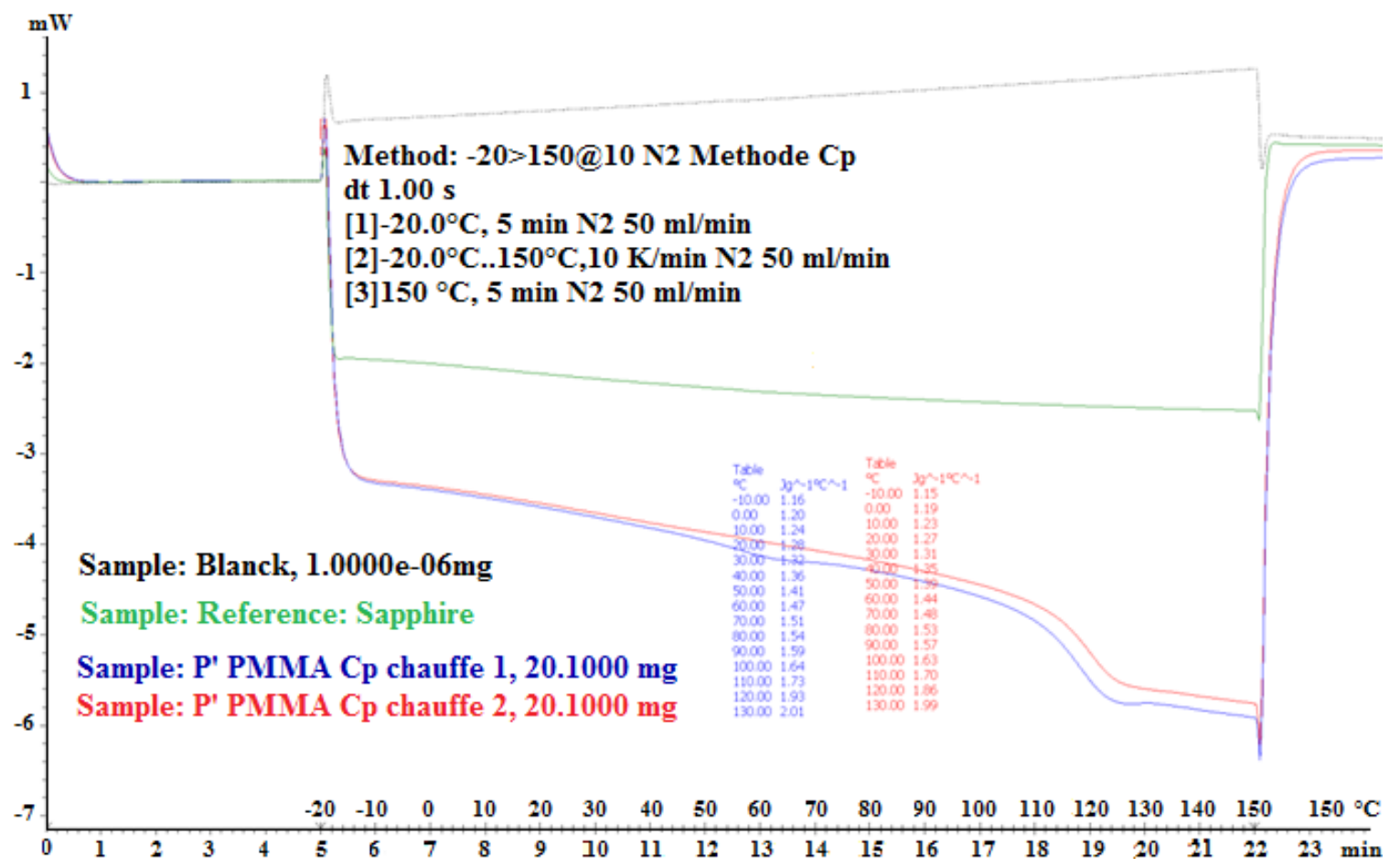


Figure 3. The variation of the Heat capacity of Black PMMA as a function of the temperature.

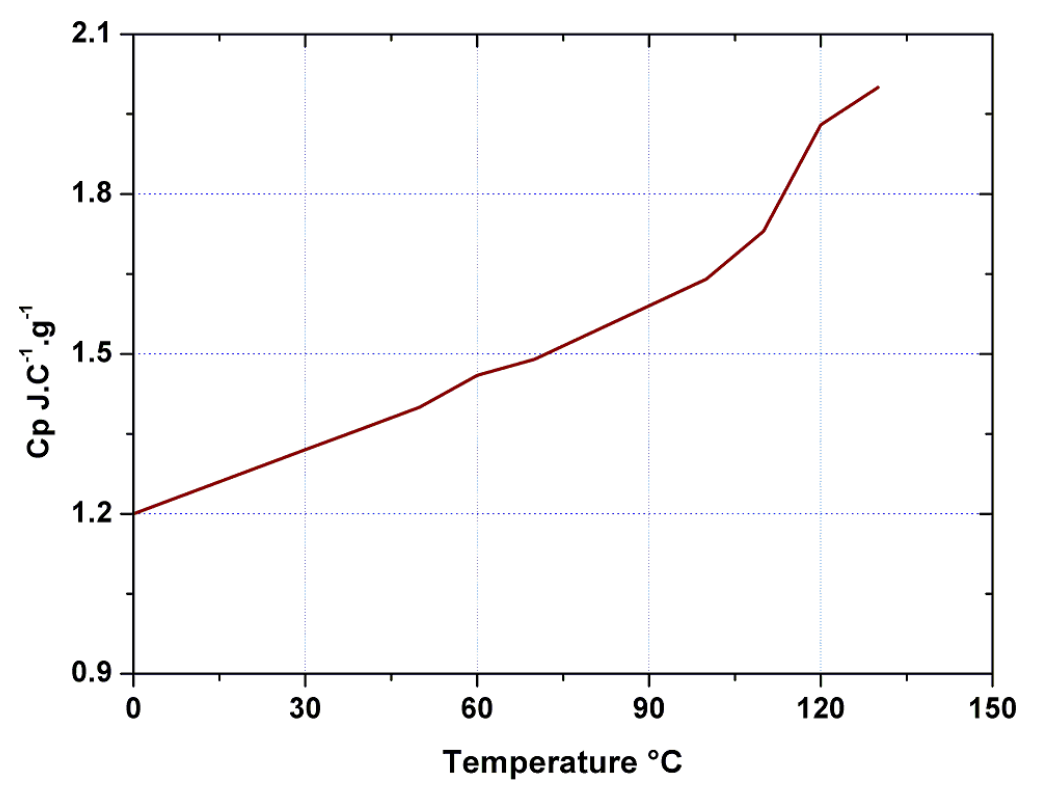

Figure 4. Mass loss (a) and Mass-loss rates (b) versus temperature for the thermal degradation of PMMA at different heating rates under nitrogen.

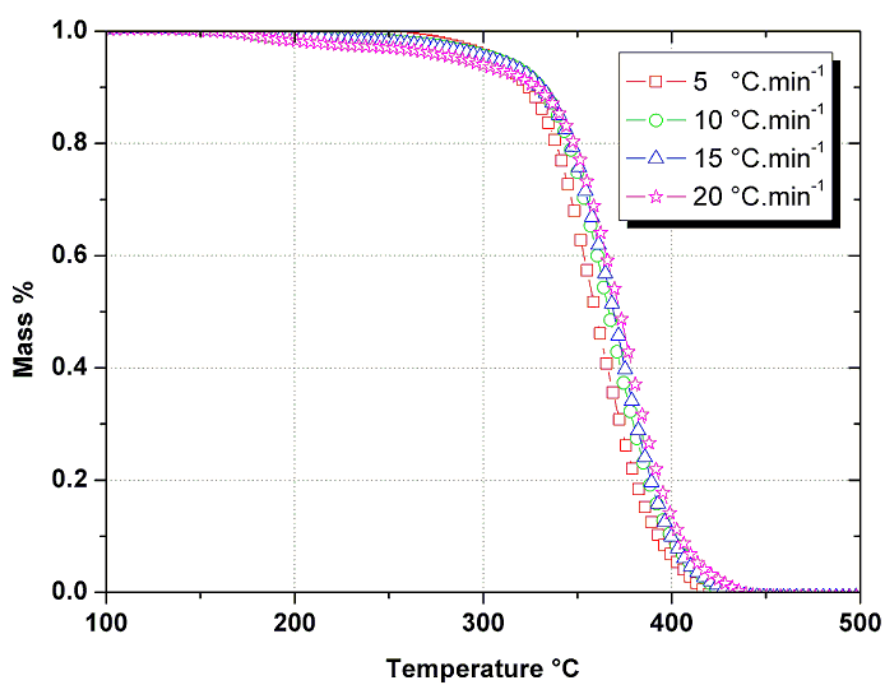

a

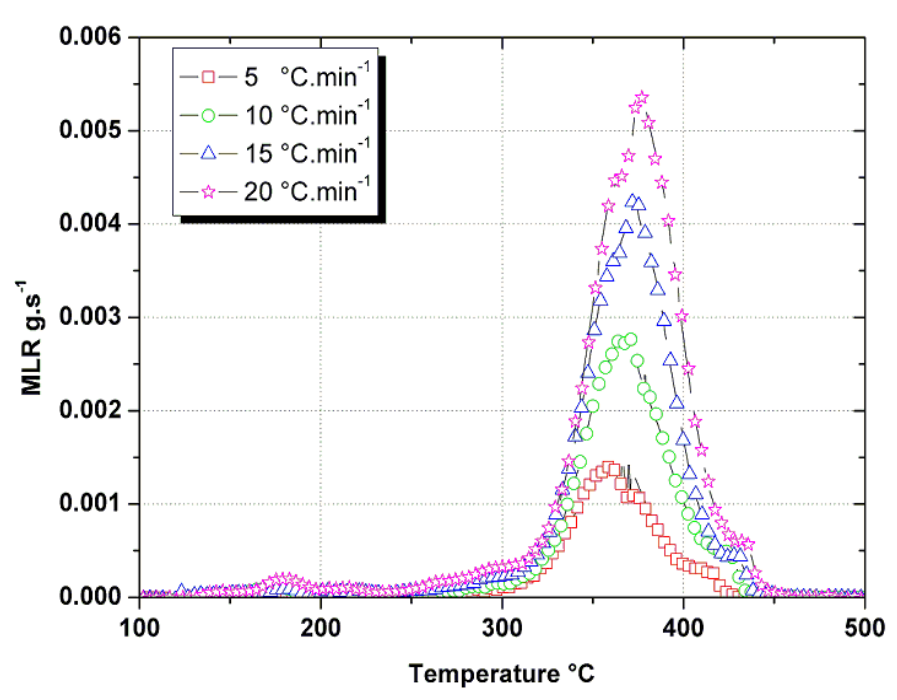

$\mathrm{b}$ 
Figure 5. Mass loss (a) and Mass-loss rates (b) versus temperature for the thermal degradation of PMMA at different heating rates in air.

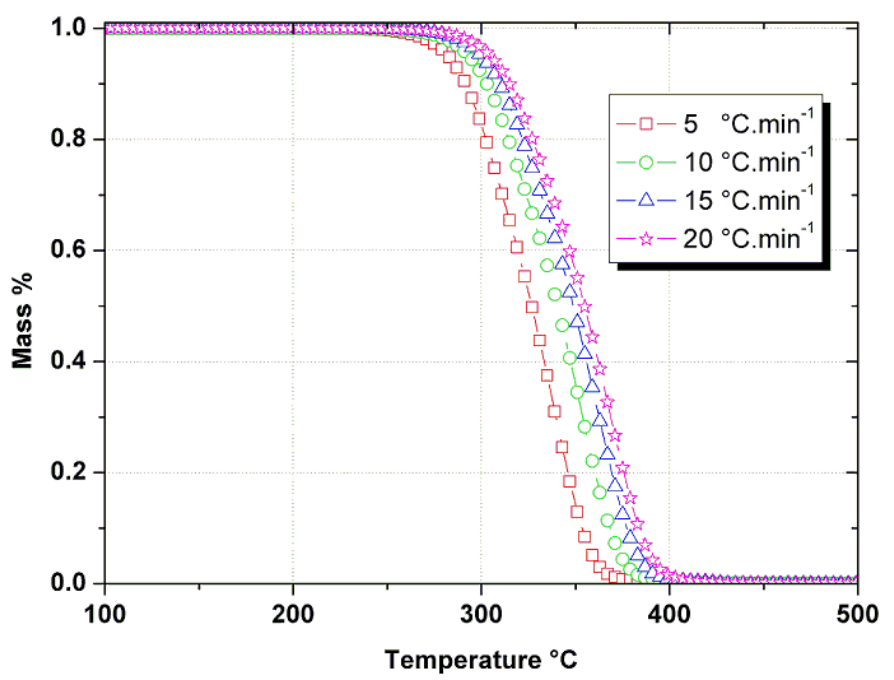

a

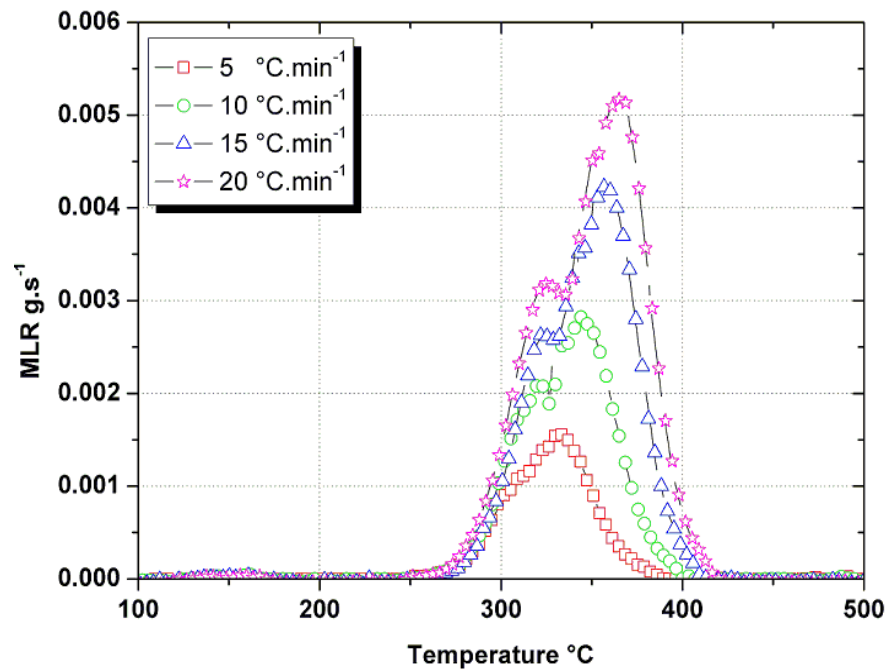

$\mathrm{b}$

Figure 6. Mass-loss rates versus temperature at $10^{\circ} \mathrm{C} / \mathrm{min}$ under nitrogen and air.

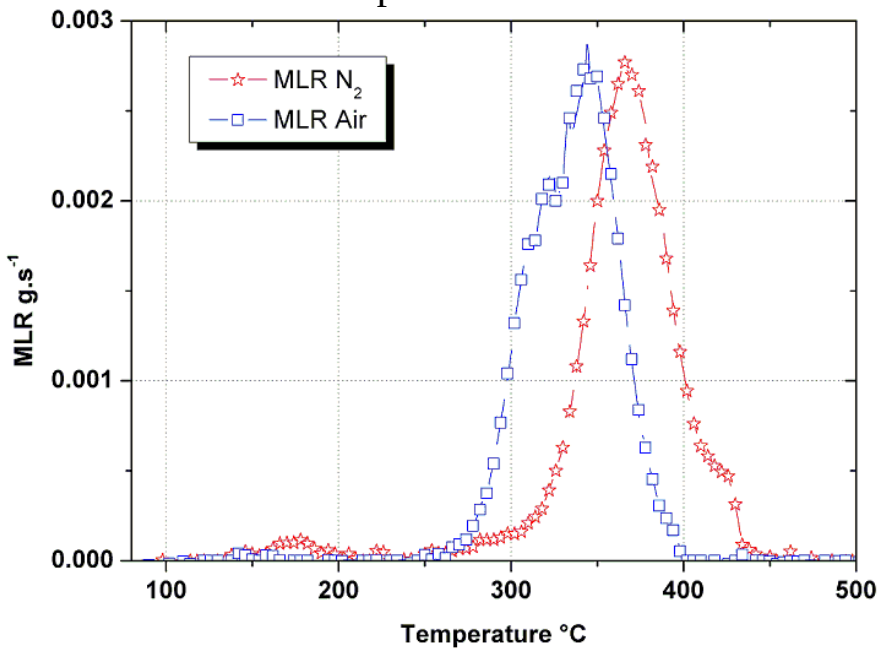


Figure 7. The evolution of the MLR and the principal gaseous components from PMMA degradation as a function of temperature, for a heating rate of $20^{\circ} \mathrm{C} / \mathrm{min}$.

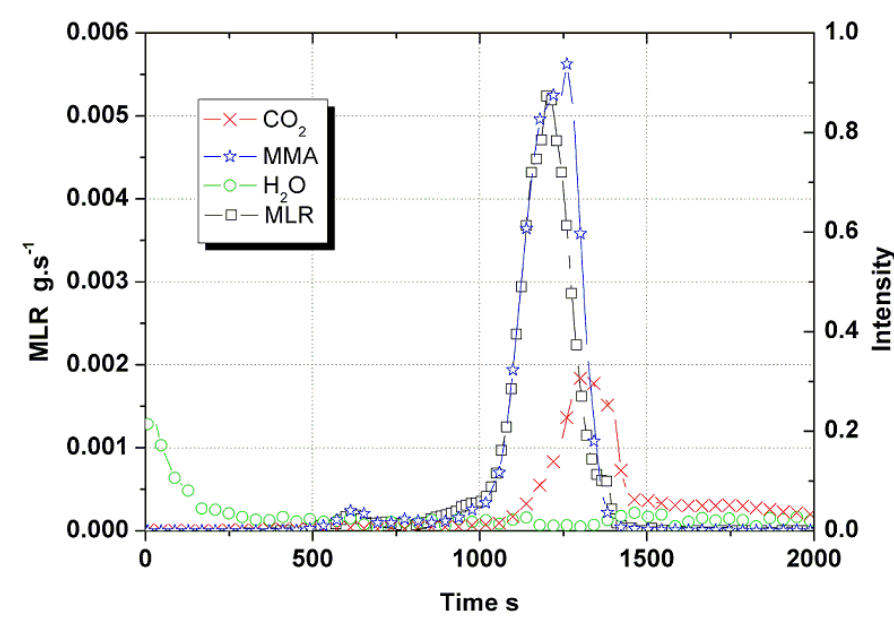

under nitrogen $\left(\mathrm{H}_{2} \mathrm{O} \times 2\right.$ and $\left.\mathrm{CO}_{2} \times 10\right)$

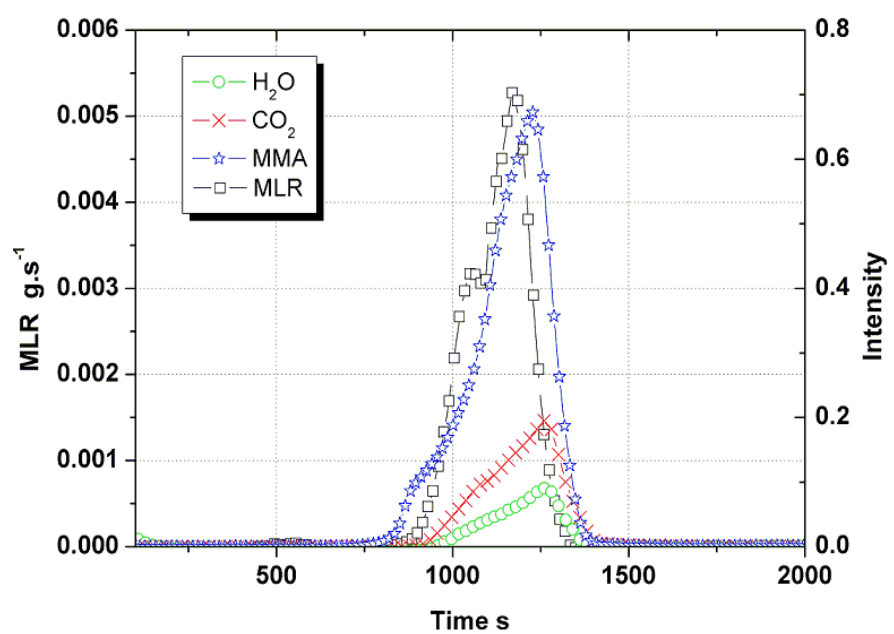

Under Air

Figure 8: The reactions occur during thermal degradation.

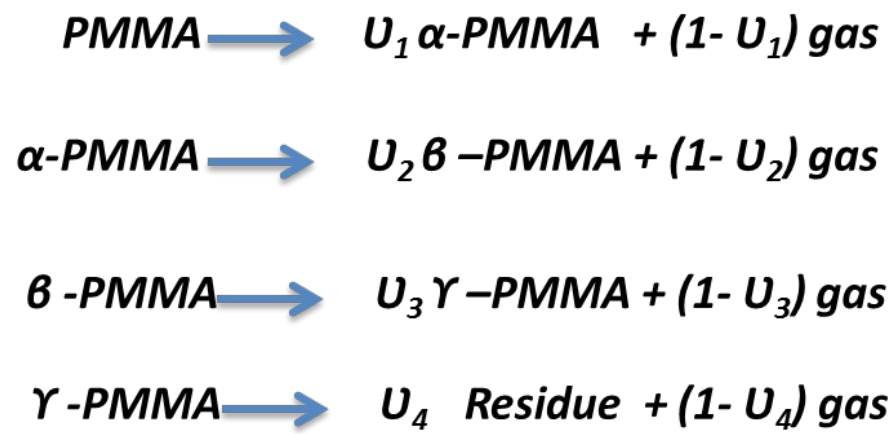


Figure 9. The theoretical and experimental curves under nitrogen

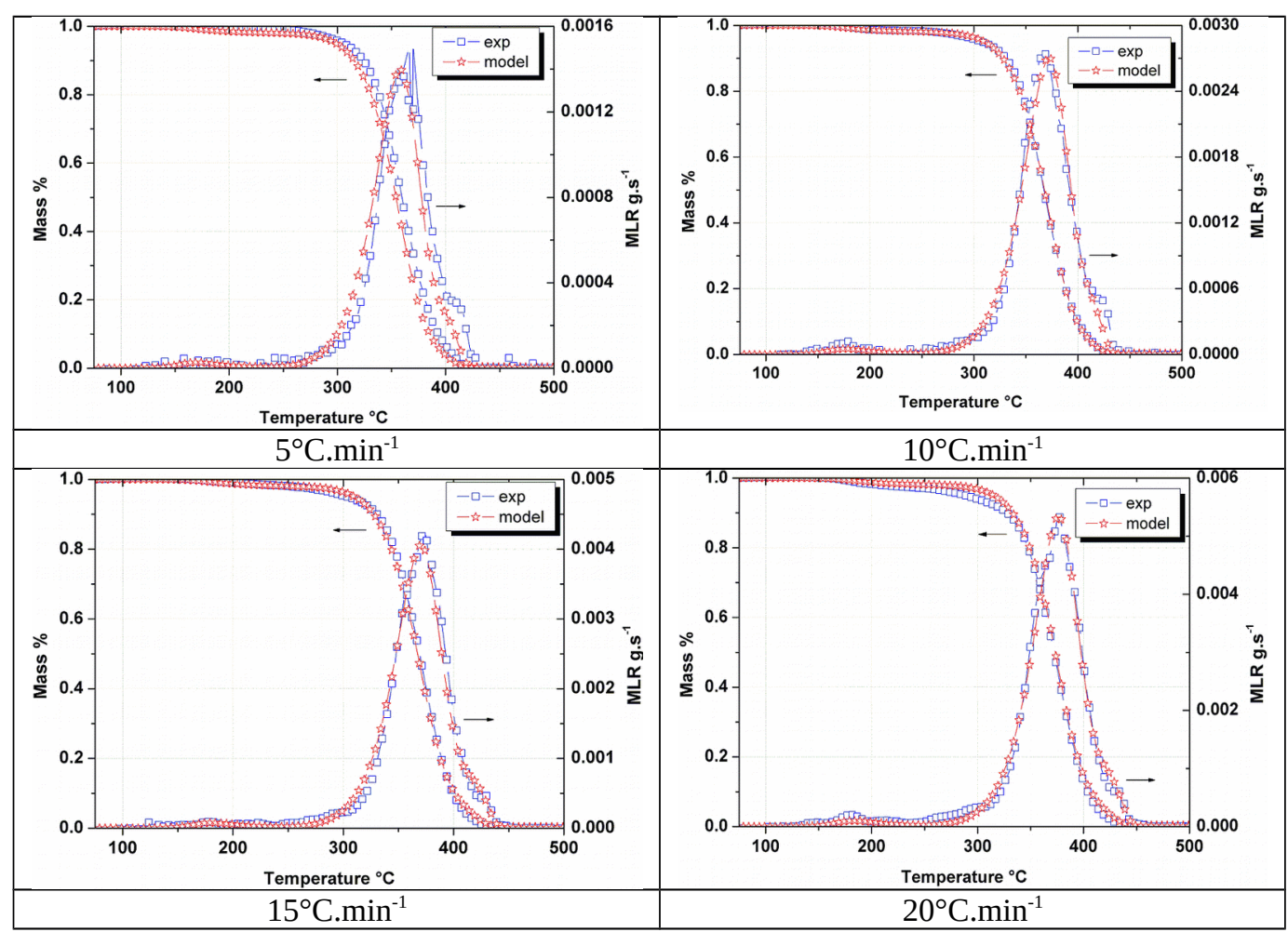


Figure 10. The theoretical and experimental curves under air.

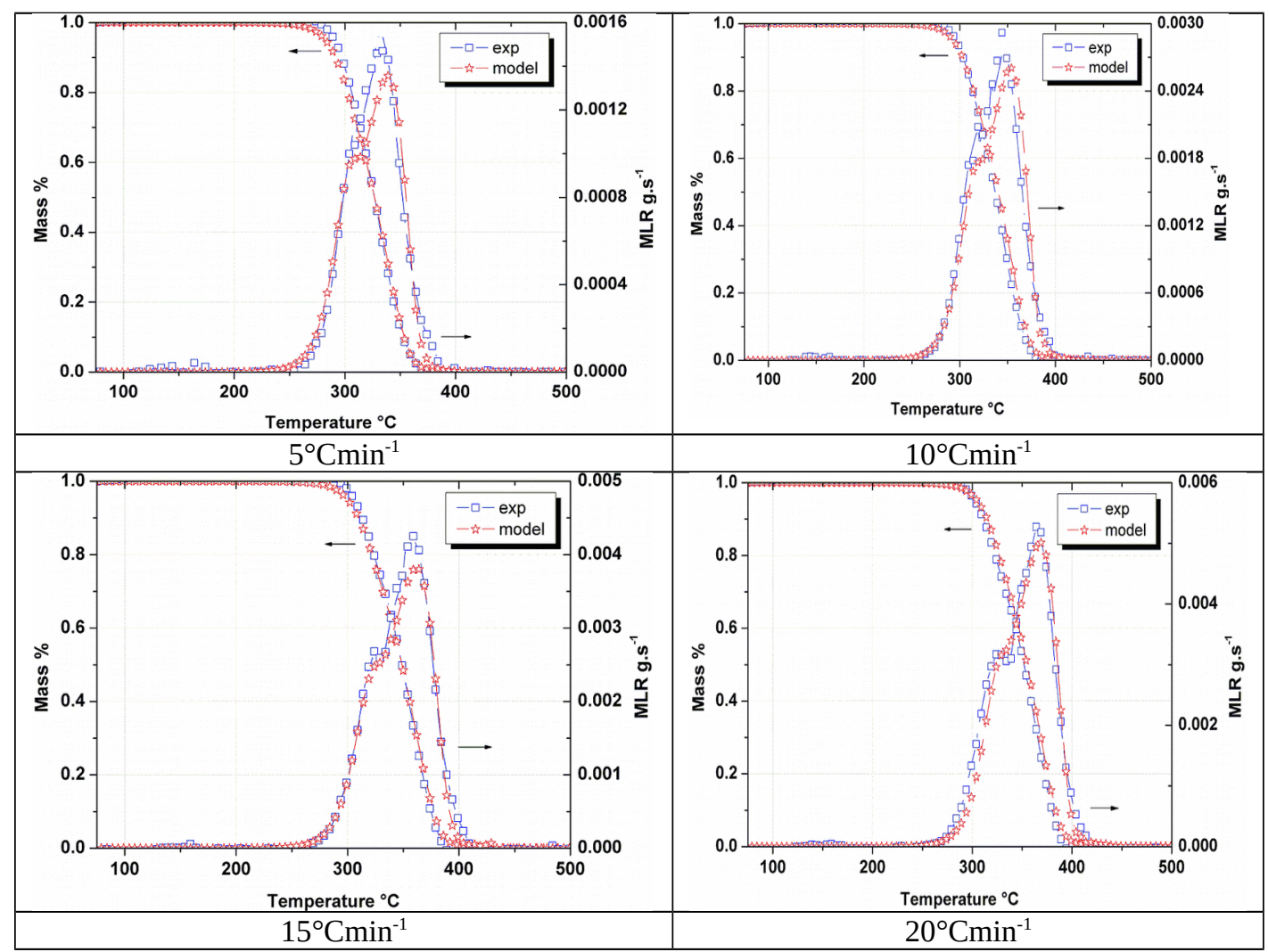

Figure 11. Comparison of the mass loss evolution for the different component in the solid phase of PMMA (heating rate $=10^{\circ} \mathrm{C} \mathrm{min}^{-1}$ ).
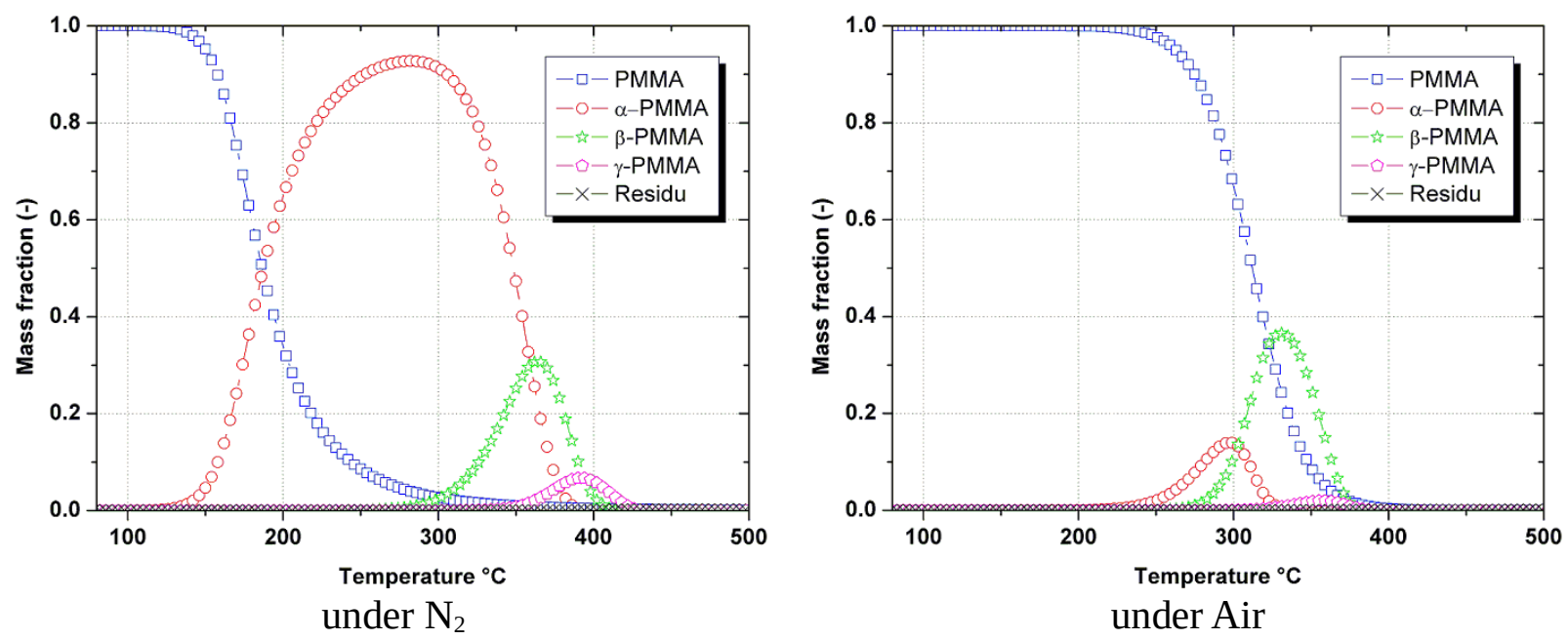
Figure 12. Comparison between the theoretical and experimental data for different heating rates

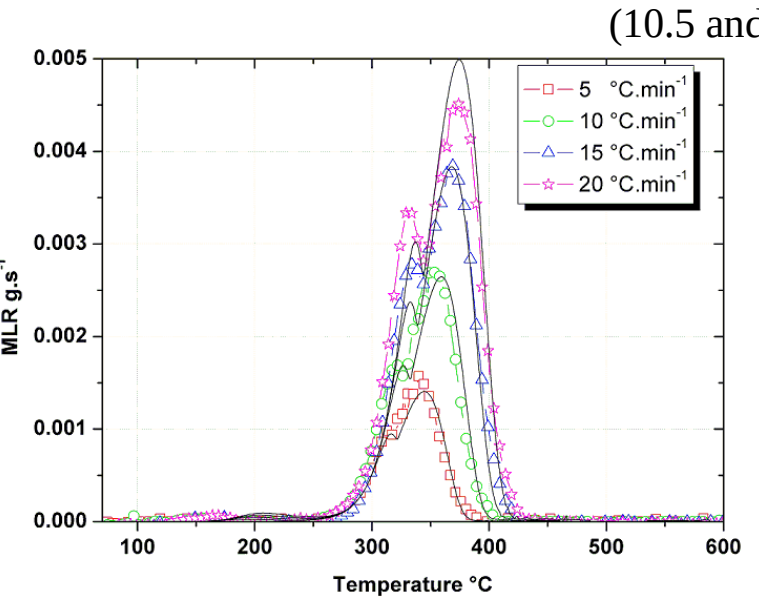

10.5 vol. $\% \mathrm{O}_{2}$

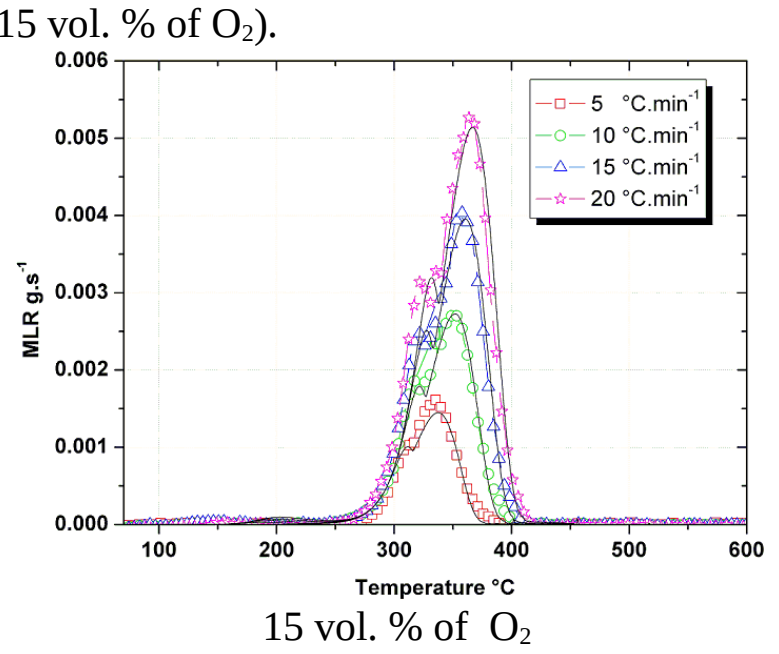

15 vol. $\%$ of $\mathrm{O}_{2}$ 